\title{
Isolated oculomotor nerve palsy: a rare manifestation of internal carotid artery dissection
}

\author{
Telma Santos, ${ }^{1}$ Hugo Morais, ${ }^{1}$ Gustavo Oliveira, ${ }^{2}$ Pedro Barros ${ }^{2}$
}

${ }^{1}$ Neurology department, Centro Hospitalar Vila Nova de Gaia/ Espinho, Vila Nova de Gaia, Portugal

${ }^{2}$ Department of Neuroradiology, Centro Hospitalar Vila Nova de Gaia/ Espinho, Vila Nova de Gaia, Portugal

\section{Correspondence to} Dr Pedro Barros, pedrojgbarros@gmail.com

Accepted 28 September 2014

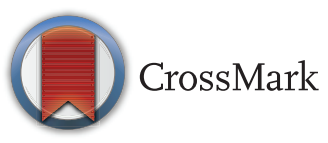

To cite: Santos T, Morais $\mathrm{H}_{\text {, }}$ Oliveira G, et al. BMJ Case Rep Published online:

[please include Day Month Year] doi:10.1136/bcr-2014205413

\section{SUMMARY}

A 58-year-old man reported sudden-onset binocular double vision that appeared 3 days earlier. He denied history of headache/cervical pain or trauma. He had a medical history of well-controlled diabetes, hypertension and dyslipidaemia. Neurological examination revealed a left-sided ptosis and binocular horizontal diplopia in dextroversion without apparent extraocular-muscle paresis or pupillary involvement. Other cranial nerves were spared as well as motor, sensory and coordination systems. There were no signs of ocular erythema, proptosis or palpable orbital mass. Brain MR angiography revealed a crescent-shaped mural hyperintensity in left internal carotid artery (ICA) at skull base, extending to intrapetrous segment, with reduced calibre and flow, suggesting a left ICA dissection. The patient was started on antiaggregation therapy. A year later he was asymptomatic and CT angiography confirmed ICA recanalisation.

\section{BACKGROUND}

Internal carotid artery dissection (ICAD) is an important cause of ischaemic stroke among young and middle-aged patients, accounting for $14-20 \%$ of all cases. ${ }^{1}$ Trauma and connective tissue disorders are well-known predisposing factors, but the majority of cases are spontaneous or related to minor/trivial trauma. ${ }^{2}$

ICAD pathophysiology lies in a compromise of structural integrity of the arterial wall through the formation of an intimal tear, resulting in stenosis, occlusion, intraluminal thrombus or extravascular haemorrhage. Most cases comprise extracranial arteries but, rarely, intracranial arteries are affected. $^{2}$

ICAD usually presents as a triad of headache/ neck pain, Horner syndrome or cerebral ischaemic symptoms. However, most patients do not show the complete triad and may exhibit less common manifestations such as cranial nerve palsies. ${ }^{2}$

Cranial nerve palsies are described in around $12 \%$ of spontaneous extracranial ICAD cases, mainly as a syndrome of lower cranial nerve palsies (IX, X, XI and XII). Isolated III (oculomotor) nerve palsy is rare, described in only 2 of 155 patients with ICAD in a case series. ${ }^{3}$

Nevertheless, the mechanism underlying these cranial neuropathies is still not fully understood. ${ }^{3-6}$

Direct compression by an enlarged dissected vessel is proposed to be responsible for lower cranial nerve palsies. However, concerning the III cranial pair, an anatomic proximity with ICA is only found within the cavernous sinus.
We present a case report on ICAD presented as III nerve palsy to emphasise the importance of considering a cervicocerebral dissection in less typical clinical presentations.

\section{CASE PRESENTATION}

A 58-year-old man came to our emergency department (ED) reporting sudden-onset persistent binocular double vision which had appeared 3 days before. He denied headache, cervical pain and trauma history.

He had medical history of well-controlled diabetes, hypertension and dyslipidaemia. Family medical history was irrelevant for stroke or connective tissue disorders.

On initial ED evaluation the patient was found to be afebrile with a blood pressure of 149/ $78 \mathrm{~mm} \mathrm{Hg}$ and a regular pulse of $75 \mathrm{bpm}$. General physical examination was normal. He showed no signs of ocular erythema, proptosis or palpable orbital mass. On neurological examination he was alert, oriented, with no evidence of higher function abnormalities. The patient presented isocoric and normally reactive pupils, partial left ptosis and, although with no obvious limitation in eye movements, the patient consistently mentioned binocular horizontal diplopia in dextroversion. There was no evidence of abnormalities involving other cranial pairs, muscle tonus and strength, osteotendinous reflexes, cutaneoplantar reflexes, sensation, coordination and gait.

\section{INVESTIGATIONS}

Laboratory screening: normal haemogram, ionogram, liver, renal, thyroid function, sedimentation rate; glycated haemoglobin $5.3 \%$; total cholesterol $215 \mathrm{mg} / \mathrm{dL}, \quad$ low-density lipoprotein cholesterol $153 \mathrm{mg} / \mathrm{dL}$, high-density lipoprotein cholesterol $46 \mathrm{mg} / \mathrm{dL}$, triglycerides $80 \mathrm{mg} / \mathrm{dL}$; hepatitis B and C, HIV and borrelia serology negative; treponema pallidum hemagglutinations assay/ Venereal Disease Research Laboratory negative.

The ECG had sinus rhythm.

Transthoracic echocardiogram was normal.

Brain non-contrast CT scan obtained in ED showed no signs of infarction.

Brain MRI angiography revealed a crescentshaped mural hyperintensity in left ICA at skull base that extends to the intrapetrous segment with reduced calibre and flow, acquiring his normal pattern in the intracavernous portion suggesting a left ICAD. Brain MRI did not show evidence of parenchymal signal abnormalities (figures 1 and 2). 


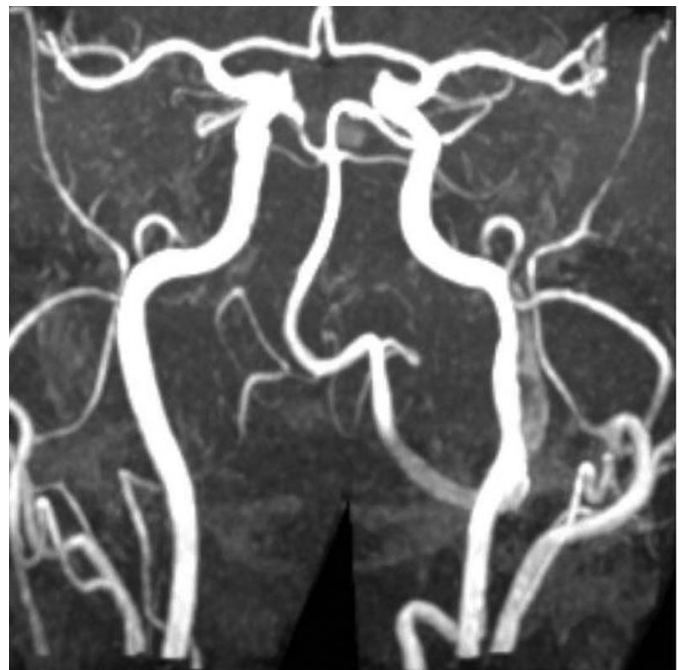

Figure 1 MR angiography showing irregularities in left internal carotid artery lumen.

\section{DIFFERENTIAL DIAGNOSIS}

Addressing a sudden-onset persistent horizontal diplopia with clinical signs of incomplete pupil-sparing oculomotor nerve palsy (partial left ptosis and diplopia maximal at dextroversion), the main differential diagnosis includes stroke and ischaemic oculomotor mononeuropathy.

The sudden onset and presence of vascular risk factors (arterial hypertension, diabetes and dyslipidaemia) favours an ischaemic aetiology. An infarct involving oculomotor nucleus is rare and clinically different from III cranial nerve palsy. Paired oculomotor nuclear complexes are located in dorsal midbrain at superior colliculus level. An infarct involving the caudal subnucleus located in midline may result in bilateral ptosis as this nucleus provides innervation for bilateral levator palpebrae superioris. As already described, our patient had a unilateral ptosis that did not support this hypothesis.

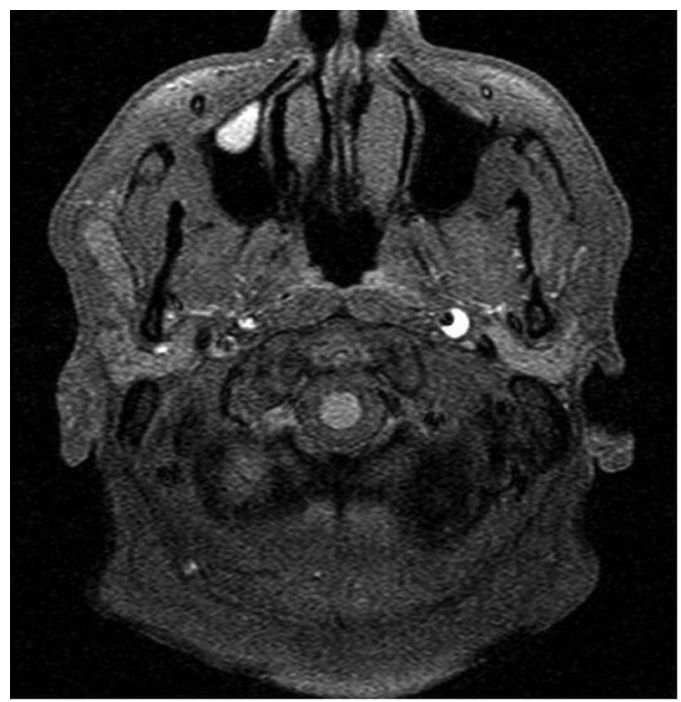

Figure 2 Fat-suppressed T1-weighted MRI showing a crescent-shaped haematoma within the wall of the left internal carotid artery, adjacent to the eccentric lumen.
Regarding the hypothesis of an ischaemic mononeuropathy, it is well known that oculomotor is the most frequent cranial nerve palsy associated with diabetes, affecting predominantly older patients with long-term diabetes. The clinical presentation has a sudden onset, usually spares pupillary involvement and can be accompanied with retro-orbital pain.

\section{TREATMENT}

Addressing a cervicocerebral artery dissection, the current accepted therapy remains antithrombotic medication (anticoagulation or antiaggregation) and there is no consistent medical evidence to guide therapy. We opted for antiaggregation therapy with $150 \mathrm{mg}$ aspirin/day.

\section{OUTCOME AND FOLLOW-UP}

After 3 months, the patient was asymptomatic and showed no abnormality in neurological examination. Brain CT confirmed ICA recanalisation and cervical doppler ultrasonography showed normal morphological and haemodynamic features.

Owing to the presence of vascular risk factors he maintains antiaggregation therapy.

\section{DISCUSSION}

The patient reported a horizontal binocular diplopia maximal when looking to the right, which, in association with left ptosis, is consistent with a left oculomotor nerve palsy. Although we were not able to observe any limitation in ocular movements, this does not exclude III nerve palsy.

It has been reported that some ICAD cases are actually asymptomatic. We do not support the hypothesis that a left oculomotor nerve palsy and a left intrapetrous ICAD are simply a manifestation of two different conditions (an ischaemic mononeuropathy and an asymptomatic ICAD). Thus, the patient has type 2 diabetes with excellent glycaemic control on oral antidiabetics and does not show evidence of microvascular/macrovascular involvement of target organs. Moreover, the patient denied ocular pain that often accompanies an ischaemic neuropathy.

Anatomically, the distal part of the III nerve is supplied by the inferior cavernous sinus and meningohypophyseal arteries, both branches from the intracavernous segment of ICA. Thus, it has been proposed that an embolic and/or haemodynamic event causing hypoperfusion of oculomotor vasa nervorum may be responsible for III paresis in the setting of ICAD involving extracavernous segments. ${ }^{4}$

ICAD presented with oculomotor nerve palsy is rare and there are few cases described in the literature. Hegde et al $l^{5}$ described a case of a 60-year-old woman with headache and evidence of a pupil-sparing oculomotor nerve palsy, which started 3 weeks after a frontal trivial trauma, with MRI features of dissection involving petrous segment of the left ICA.

There are also reports of cases involving extracranial ICA segment. Campos et $a l^{6}$ described a case of a 50-year-old man who began having an occipital headache and developed diplopia days later, with objective impairment in right eye adduction and upward gaze and slight pupillary dilation with MR angiography evidence of a dissection of right extracranial ICA. Nizam et $a l^{7}$ described a case of a 24-year-old man presenting a right hemianopsia, hemiparesis and hemihypestaesia 2 days after the onset of a right complete oculomotor nerve palsy, with MRI evidence of a dissection involving extracranial left ICAD and an acute infarct in left middle cerebral artery. 


\section{Learning points}

- Internal carotid artery dissection (ICAD) cases may present without the more common clinical signs, such as Horner syndrome, headache/neck pain or focal neurological ischaemic signs.

- Although rare, cranial nerve palsies can be the only manifestation of an ICAD.

- Considering the small group of patients presenting cranial nerve palsies in the setting of an ICAD, oculomotor nerve involvement is extremely rare.

- The hypothesis of a cervicocerebral dissection should be considered when addressing a young patient with cranial nerve palsy.

Contributors TS and PB wrote the article. HM corrected and revised it. GO was responsible for the selection and review of imaging components.
Funding None.

Competing interests None.

Patient consent Obtained.

Provenance and peer review Not commissioned; externally peer reviewed.

\section{REFERENCES}

1 Bogousslavsky J, Pierre P. Ischemic stroke in patients under 45 years. Neurol Clin 1992:10:113-24.

2 Fusco MR, Harrigan MR. Cerebrovascular dissections-a review part I: spontaneous dissections. Neurosurgery 2011;68:242-57.

3 Mokri B, Silbert PL, Schievink WI, et al. Cranial nerve palsy in spontaneous dissection of the extracranial internal carotid artery. Neurology 1996;46:356-9.

4 Wessels T, Röttger C, Kaps M, et al. Upper cranial nerve palsy resulting from spontaneous carotid dissection. J Neurol 2005;252:453-6.

5 Hegde V, Coutinho CM, Mitchell JD. Dissection of the intracranial internal carotid artery producing isolated oculomotor nerve palsy with sparing of pupil. Acta Neurol Scand 2002;105:330-2.

6 Campos CR, Massaro AR, Scaff M. Isolated oculomotor nerve palsy in spontaneous internal carotid artery dissection: case report. Arq Neuropsiquiatr 2003;61:668-70.

7 Nizam A, Yacoub HA, McKinney JS. Internal carotid artery dissection heralded by an oculomotor nerve palsy: case report and literature review. Neurologist 2011;17:333-7.

Copyright 2014 BMJ Publishing Group. All rights reserved. For permission to reuse any of this content visit

http://group.bmj.com/group/rights-licensing/permissions.

BMJ Case Report Fellows may re-use this article for personal use and teaching without any further permission.

Become a Fellow of BMJ Case Reports today and you can:

- Submit as many cases as you like

- Enjoy fast sympathetic peer review and rapid publication of accepted articles

- Access all the published articles

- Re-use any of the published material for personal use and teaching without further permission

For information on Institutional Fellowships contact consortiasales@bmjgroup.com

Visit casereports.bmj.com for more articles like this and to become a Fellow 